\title{
Homogeneity of pollen allele frequencies of single seed trees in Picea abies (L.) Karst. plantations
}

\author{
R. FINKELDEY* \\ Abteilung für Forstgenetik und Forstpflanzenzüchtung, Universität Göttingen, Büsgenweg 2, 37077 Göttingen, Germany
}

\begin{abstract}
Allelic frequency distributions of genetically effective pollen clouds, which pollinated a total of 21 single seed trees in three populations of Norway spruce (Picea abies (L.) Karst.), were determined at seven polymorphic isozyme marker loci and compared with genetic structures of population samples. Differentiation among populations and among pollen allele frequencies of single seed trees within populations is low. In general, genetic distances between pollen and population gene pools are small. Both population and single tree outcrossing rates are high. Deviations from random mating are statistically significant at several marker loci for single seed trees. Results indicate extensive gene flow by pollen both within and among populations, which may counteract adaptive and nonadaptive processes of genetic differentiation.
\end{abstract}

Keywords: conifer, gene flow, isozyme markers, mating system, Picea abies, pollen dispersal.

\section{Introduction}

The dynamics of genetic structures at marker loci during the reproductive phase of plant populations have attracted much interest as they allow investigation of aspects of the mating system and gene flow, both of which are crucial components of the species' genetic system. The interpretation of experiments has usually been based on specific models of the mating system, and results have been utilized to infer critical parameters of these models.

The most frequently estimated mating system parameter is the proportion of zygotes arising from selffertilization $s$ or its complement, the 'outcrossing rate' $t=1-s$. The estimation procedure is usually based on a mixed-mating model, which assumes that each seed results either from selfing or from random outcrossing (Brown \& Allard, 1970). If estimation rests on an unstructured random sample of the progeny generation, a single population selfing proportion is computed. In that case homogeneity of individual plant selfing rates and of the outcrossed pollen pool of all plants are among the assumptions of the model (Schoen \& Clegg, 1984). The violation of assumptions frequently leads to considerable heterogeneity among estimates of selfing rates based on different single gene

*Correspondence: UNDP/FAO Project RAS/91/004, ERDB Building, PO Box 157, College, Laguna 4031, Philippines.

c 1995 The Genetical Society of Great Britain. loci within the same population and/or biologically meaningless outcrossing rates well above one, i.e. negative selfing rates (e.g. Brown et al., 1985). Computation of averages over several gene loci and multilocus estimates of selfing rates may improve the interpretation of experimental results (Ritland \& Jain, 1981; Shaw et al., 1981), but do not allow testing of crucial assumptions of the model.

If single plant progeny arrays are available, it is possible to estimate individual selfing rates for these plants and to gain an idea of the variability of $s$ within the population and of the heterogeneity of pollen allele frequencies among different plants (Ritland \& ElKassaby, 1985). Hence, it is possible to test the assumption of uniform outcross pollen allele frequencies (Fu et al., 1992) of the mixed-mating model. However, even for single seed plants biologically meaningless individual outcrossing rates significantly greater than one are frequently observed and indicate the violation of model assumptions.

The mating system determines the frequency distributions of genetic types within the progeny generation. Unless all fertilization is by selfing, the proportion of self-fertilization is not the only determinant of these frequency distributions. Additional determinants are, for example, positive or negative assortative mating. The higher the outcrossing rate, the greater becomes the significance of possible heterogeneity among the outcrossed pollen pool of single plants. 
For predominantly outcrossing species, as are most forest trees including conifers, genetic frequency distributions of the progeny generation are substantially influenced by the effectiveness of gene flow via pollen within and among populations. Hence, an investigation of the spatial distribution of male gametes associated with mating events may offer more insight into adaptive strategies of plant populations than the sole estimation of certain mating system parameters.

In fact, the mating system of a population and the gene flow by pollen within a population are closely associated phenomena. It is, however, inappropriate to measure the amount of pollen flow in terms of the outcrossing rate (see Govindaraju, 1988). Complete outcrossing may occur together with restricted gene flow by pollen, eventually leading to subpopulation differentiation, or with effective pollen flow. The same experimental investigations may be suitable to estimate mating system parameters and the effectiveness of gene flow within populations. Nevertheless, it is useful to distinguish the two concepts, as the mating system determines overall genetic frequency distributions within the progeny generation, whereas gene flow by pollen affects the spatial arrangement of genetic types.

From an ecological and evolutionary perspective, the spatial distribution of genetic types is a crucial component of the plant's genetic system. Once established, immobile plants must be able to cope with environmental conditions at their respective growth sites. Thus, the survival of a population depends on its ability not only to generate adapted, namely surviving and reproducing, genotypes for a specific site, but also to distribute these genotypes in accordance with the patchiness of the environment (Gregorius, 1985). If, for example, large ecologically distinct sites remain constant over long periods relative to the generation cycle of the species, restricted gene flow by pollen and seed may help to establish well-adapted subpopulations. Extensive gene flow may counteract the formation of such neighbourhoods. If, on the other hand, the environment changes drastically and irregularly over short distances and over time, extensive gene flow within populations, preferably both by pollen and seeds, together with abundant seed production, will help to allocate adapted genotypes to all distinct microsites.

In this paper I describe genetic structures at seven isozyme marker loci in three populations of Norway spruce (Picea abies (L.) Karst.). Emphasis is on an interpretation of the results with regard to gene flow via pollen within pure spruce stands, but mating system parameters, i.e. population and single tree selfing rates, are estimated as well. Two questions will be dealt with in detail. (i) What is the degree of genetic differentiation among populations and among single tree pollen clouds within populations? (ii) Is there a potential for adaptive or nonadaptive genetic differentiation among populations or will differentiation processes be prevented by extensive gene flow within and among populations?

The seed of Norway spruce, like that of most other conifers and all members of the Pinaceae investigated so far, contains a diploid embryo and a haploid ('primary') endosperm, which develops from macrogametophyte tissue and hence represents the maternal contribution to the genotype of the embryo at any gene locus. It is easily possible to infer the paternal contribution to each embryo simply by comparing the genotype of the embryo with the genetic information of the endosperm (Müller, 1977). Hence, pollen allele frequencies or 'single tree pollen clouds' may be measured reliably irrespective of the genotype of a seed tree at a specific gene locus.

\section{Materials and methods}

Seeds were harvested in three Norway spruce (Picea abies) populations of the Sauerland, a hilly region in western Germany. The Sauerland is located outside the natural distribution area of Norway spruce; all populations are plantations, which represent the first generation of Norway spruce cultivation at their respective sites. Plantations were established between 1850 and 1910; their altitude varies between 390 and $720 \mathrm{~m}$. All populations are pure, dense Norway spruce forests. The sizes of the plantations are 2.8 ha (population I), 14.3 ha (population II) and 6.8 ha (population III). All populations are surrounded by extensive forests mostly dominated by Norway spruce. The populations are widely separated by a distance of several kilometers between populations I and II, and over $40 \mathrm{~km}$ between these plantations and population III.

Seeds were harvested by climbing single seed trees randomly distributed over the entire plantation; single tree progeny arrays were carefully kept separately. Sample sizes were 98 seed trees for population I, 99 for population II and 77 trees for population III. Most seeds were prepared for long-term storage at the Forest Tree Gene Bank in Obereimer (Arnsberg), but small seed samples were investigated for variation at isozyme marker loci by means of horizontal starch gel electrophoresis at the Abteilung für Forstgenetik, Universität Göttingen. Details of laboratory techniques, genetic analysis, and genotyping are described elsewhere (Bergmann, 1973; Finkeldey, 1993, unpublished). Six enzyme systems were scored for variation: leucine aminopeptidase (LAP; E.C. 3.4.11.1), glutamateoxaloacetate transaminase (GOT; E.C. 2.6.1.1), phosphoglucose isomerase (PGI; E.C. 5.3.1.9), glucose-6-phosphate dehydrogenase (G-6-PDH; E.C. 
1.1.1.49), 6-phosphogluconate dehydrogenase (6PGDH; E.C. 1.1.1.44) and malate dehydrogenase (MDH; E.C. 1.1.1.37). A total of 14 gene loci code for these enzyme systems. In this study, reference will be made only to those seven polymorphic loci for which the frequency of the most frequent allele is below 95 per cent in at least one population. These loci are $L A P$ $B, \quad G O T-B, \quad P G I-B, \quad G-6-P D H-A, \quad 6-P G D H-B$, 6-PGDH-C and $M D H-C$.

The genotypes of all seed trees at these marker loci were determined by an investigation of a sample of endosperms from each tree. At least six endosperms per tree were scored, as in that case the probability of misclassification of a heterozygous seed tree at a specific gene locus as a homozygote for one of its alleles is below 5 per cent (exactly $0.5^{6-1}=0.03125$ assuming regular segregation; see Ritland \& ElKassaby, 1985). Allele frequencies of the populations were computed on the basis of these data (abbreviation: Pop).

In each of the three populations, seven trees were selected to estimate the pollen allele frequencies in their genetic effective individual pollen clouds, i.e. among the pollen that sired the seeds of each tree (abbreviation: Single tree pollen cloud = Sitpoc). . Some trees were selected because they showed a previously unobserved isozyme phenotype in some endosperms for one of the investigated enzyme systems; in that case the observation of segregation ratios within the endosperms of that tree was used to confirm the allelic status of the phenotype in question to an already identified gene locus. The remaining trees were selected at random. A sample of 100 seeds was investigated from each of these 21 trees; both endosperm and embryo tissue were investigated from each seed. The paternal contribution to each seed was determined by 'subtracting' the allele of the endosperm, i.e. the maternal contribution, from the genotype of the embryo. On this basis I estimated individual pollen cloud allele frequencies for these 21 seed trees at each of the seven polymorphic gene loci. Joint pollen allele frequencies were computed for each population by pooling all seven individual genetic effective pollen clouds of the population (abbreviation: Pooled pollen cloud $=$ Popoc ) .

Allelic diversities $v=\left(\Sigma_{i} p_{\mathrm{i}}^{2}\right)^{-1}$ (Gregorius, 1987) were calculated for all of the 21 Sitpocs, the three Popocs and the three Pops. The diversity $v$ equals the 'differentiation effective number of alleles' at a gene locus (Crow \& Kimura, 1970, p. 323ff.). The gene pool diversity was computed as the harmonic mean of single locus values (Gregorius, 1987). Allelic distances between Sitpocs and Pops as well as between Popocs and Pops were computed as $d_{\mathrm{o}}\left(p, p^{\prime}\right)=0.5 \Sigma_{\mathrm{i}}\left|p_{\mathrm{i}}-p_{1}^{\prime}\right|$ (Gregorius, 1974). Subpopulation differentiation was measured following Gregorius \& Roberds (1986; $D_{i}$ and $\delta$ values) and by the $G_{\mathrm{ST}}$ statistics of Nei (1973), which are equivalent to the $F_{\mathrm{ST}}$ statistics of Wright (1969, p. 294ff.). Gene pool distances and differentiation were computed as arithmetic means of single locus estimates. Allelic differentiation was measured among Pops and Popocs as well as among Sitpocs within each population. A hierarchical analysis of the total gene diversity among all 21 investigated Sitpocs was performed (Nei, 1973): I partitioned the total gene diversity $\left(H_{\mathrm{T}}\right)$ into a component of diversity among populations $\left(D_{\mathrm{PT}}\right)$, within populations $\left(D_{\mathrm{SP}}\right)$, and within Sitpocs $\left(H_{\mathrm{S}}\right)$, and computed the proportion of the total diversity resulting from diversity among populations $\left(G_{\mathrm{PT}}=D_{\mathrm{PT}} / H_{\mathrm{T}}\right)$ and resulting from diversity within populations $\left(G_{\mathrm{SP}}=D_{\mathrm{SP}} / H_{\mathrm{T}}\right)$.

Heterogeneity among allelic frequency distributions was checked for statistical significance by means of the log likelihood ratio test ( $G$-test; Sokal \& Rohlf, 1981, p. $695 \mathrm{ff}$.). Rare alleles were lumped before the $G$-test was performed to avoid problems associated with low expected frequencies (Sokal \& Rohlf, 1981, p. 709). With the exception of the $L A P-B$ locus, for which three allelic types could be distinguished $\left(B_{1}, B_{2}\right.$, all other alleles), I grouped all alleles except the most frequent type before the $G$-test was performed. The GSED (E. Gillet, unpublished) and BIOsYs-1 (Swofford \& Selander, 1981) computer programs were used to calculate all diversity, distance and differentiation measures, as well as to perform log likelihood ratio tests.

Population and single tree outcrossing rates were estimated using the maximum likelihood procedure of Ritland \& Jain (1981). This estimation does not take into account the additional information given by ordered genotypes, i.e. the possibility to distinguish between the maternal and paternal contributions to each progeny by means of endosperm analysis in gymnosperms. However, the consideration of ordered genotypes would not significantly increase the efficiency of the procedure for this data set (see Ritland \& El-Kassaby, 1985). Standard deviations were computed by the 'bootstrap method' (100 bootstraps; Ritland, 1990). For an estimation of single tree outcrossing rates, both the outcrossing rate and pollen allele frequencies were assumed to vary among families and were estimated jointly. Absence of linkage is one of the assumptions of the multilocus estimation (Ritland \& Jain, 1981); according to Muona et al. (1987) and Geburek \& von Wuehlisch (1989), the loci investigated in this study are not strongly linked in Picea abies. Computations were performed with the aid of the MLT computer program of Ritland (1990). 


\section{Results}

\section{Allelic diversities}

Single locus and gene pool allelic diversities for each Sitpoc (T1-T7), for the Popoc of each population (pooled), and for the population sample (Pop) are shown in Table 1. There are clear differences among loci. High diversities are observed at the GOT-B, PGI$B, 6-P G D H-B$ and 6-PGDH-C loci, all of which are characterized by the occurrence of two alleles at frequencies above 20 per cent in all samples (frequency data are not presented). The G-6-PDH-A and $M D H-C$ loci are less diverse; they are both characterized by a frequent type (frequency above 80 per cent in all samples) and a series of rare alleles. The $L A P-B$ locus is dominated by a single allele as well, but the frequencies of two other types are between 5 and 15 per cent in most samples, and several other rare alleles (frequency below 5 per cent) were observed.

Gene pool diversities of Sitpocs differ only slightly across all populations between 1.413 ( $\mathrm{T} 4$ of population I) and 1.572 ( 77 of population II). With only few exceptions, diversities of the Pops are slightly higher than corresponding diversities of the Popocs.

\section{Differentiation among populations}

Allelic differentiation among populations is computed both on the basis of the Pops (Table 2) and on the basis of Popocs (Table 3). In spite of large sample sizes of between 77 and 99 diploid genotypes, i.e. between 154

Table 1 Allelic diversity $v=\left(\Sigma_{i} p_{i}^{2}\right)^{-1}$ (Gregorius, 1987) of seven single tree pollen clouds ('Sitpocs'; T 1 to T 7 ), of the pooled pollen cloud of these seven trees ('Popocs'; pooled), and of the population sample ('Pop'; Population) for each of the three investigated populations of Picea abies

\begin{tabular}{|c|c|c|c|c|c|c|c|c|c|}
\hline $\begin{array}{c}\text { Population I } \\
\qquad N\end{array}$ & $\begin{array}{l}\text { T } 1 \\
100\end{array}$ & $\begin{array}{l}\text { T } 2 \\
100\end{array}$ & $\begin{array}{l}\text { T } 3 \\
100\end{array}$ & $\begin{array}{l}\text { T } 4 \\
100\end{array}$ & $\begin{array}{l}\text { T } 5 \\
100\end{array}$ & $\begin{array}{l}\text { T } 6 \\
100\end{array}$ & $\begin{array}{l}\text { T } 7 \\
100\end{array}$ & $\begin{array}{l}\text { Pooled } \\
700\end{array}$ & $\begin{array}{c}\text { Population } \\
196\end{array}$ \\
\hline$L A P-B$ & 1.364 & 1.341 & 1.585 & 1.540 & 1.801 & 1.459 & 1.427 & 1.501 & 1.505 \\
\hline$G O T-B$ & 1.994 & 2.043 & 1.990 & 1.493 & 1.972 & 1.936 & 2.030 & 1.953 & 1.946 \\
\hline$P G I-B$ & 1.600 & 1.574 & 1.676 & 1.574 & 1.651 & 1.700 & 1.600 & 1.625 & 1.534 \\
\hline$G-6-P D H-A$ & 1.107 & 1.128 & 1.326 & 1.062 & 1.083 & 1.203 & 1.127 & 1.145 & 1.204 \\
\hline 6-PGDH-B & 1.569 & 1.814 & 1.574 & 1.784 & 1.663 & 1.596 & 1.635 & 1.673 & 1.715 \\
\hline 6-PGDH-C & 1.873 & 2.299 & 2.000 & 1.793 & 1.980 & 1.987 & 1.999 & 2.015 & 2.020 \\
\hline$M D H-C$ & 1.106 & 1.083 & 1.150 & 1.062 & 1.128 & 1.084 & 1.041 & 1.097 & 1.157 \\
\hline Gene pool & 1.447 & 1.500 & 1.559 & 1.413 & 1.527 & 1.498 & 1.465 & 1.498 & 1.521 \\
\hline $\begin{array}{c}\text { Population II } \\
N\end{array}$ & & & & & & & & & $\begin{array}{c}\text { Population } \\
198\end{array}$ \\
\hline$L A P-B$ & 1.463 & 1.483 & 1.603 & 1.334 & 1.703 & 1.491 & 1.697 & 1.541 & 1.624 \\
\hline GOT-B & 2.082 & 2.104 & 1.691 & 1.899 & 1.950 & 2.030 & 2.197 & 2.010 & 1.911 \\
\hline$P G I-B$ & 1.497 & 1.600 & 1.497 & 1.700 & 1.368 & 1.676 & 1.835 & 1.600 & 1.832 \\
\hline$G-6-P D H-A$ & 1.297 & 1.105 & 1.173 & 1.151 & 1.105 & 1.084 & 1.084 & 1.139 & 1.298 \\
\hline $6-P G D H-B$ & 1.760 & 1.793 & 1.651 & 1.586 & 1.987 & 1.746 & 2.089 & 1.809 & 2.073 \\
\hline 6- $P G D H-C$ & 1.873 & 1.814 & 1.950 & 1.950 & 1.972 & 1.993 & 1.923 & 1.969 & 1.980 \\
\hline$M D H-C$ & 1.041 & 1.041 & 1.020 & 1.062 & 1.173 & 1.084 & 1.062 & 1.068 & 1.177 \\
\hline Gene pool & 1.497 & 1.474 & 1.448 & 1.453 & 1.522 & 1.496 & 1.572 & 1.506 & 1.631 \\
\hline $\begin{array}{c}\text { Population III } \\
N\end{array}$ & & & & & & & & & $\begin{array}{c}\text { Population } \\
154\end{array}$ \\
\hline$L A P-B$ & 1.359 & 1.308 & 1.455 & 1.437 & 1.685 & 1.283 & 1.395 & 1.415 & 1.729 \\
\hline GOT-B & 2.095 & 1.691 & 1.982 & 1.880 & 1.952 & 2.015 & 2.040 & 2.010 & 1.895 \\
\hline$P G I-B$ & 1.574 & 1.445 & 1.497 & 1.748 & 1.523 & 1.972 & 1.651 & 1.647 & 1.721 \\
\hline$G-6-P D H-A$ & 1.127 & 1.196 & 1.196 & 1.342 & 1.268 & 1.127 & 1.243 & 1.213 & 1.213 \\
\hline $6-P G D H-B$ & 1.665 & 1.809 & 1.742 & 1.471 & 1.471 & 1.758 & 1.506 & 1.631 & 1.685 \\
\hline $6-P G D H-C$ & 1.972 & 1.972 & 1.987 & 1.997 & 1.997 & 1.997 & 1.873 & 1.991 & 2.051 \\
\hline$M D H-C$ & 1.105 & 1.173 & 1.198 & 1.220 & 1.000 & 1.173 & 1.196 & 1.150 & 1.200 \\
\hline Gene pool & 1.474 & 1.459 & 1.519 & 1.540 & 1.479 & 1.524 & 1.505 & 1.515 & 1.582 \\
\hline
\end{tabular}

$N$, sample size. 
Table 2 Allelic differentiation among population samples of Picea abies ('Pops'); $D_{j}$ and $\delta$ (Gregorius \& Roberds, 1986), $G_{\mathrm{ST}}$ (Nei, 1973) and results of a log likelihood ratio test of homogeneity of the allelic frequency distributions $(G$-test: 4 d.f. for $L A P-B$ and 2 d.f. for all other loci; Sokal \& Rohlf, 1981)

\begin{tabular}{lcccccc}
\hline \multirow{7}{*}{$N$} & \multicolumn{7}{c}{$D_{j}$} \\
\cline { 2 - 5 } & $\begin{array}{c}\text { Pop. I } \\
196\end{array}$ & $\begin{array}{c}\text { Pop. II } \\
198\end{array}$ & $\begin{array}{c}\text { Pop. III } \\
154\end{array}$ & $\delta$ & $G_{\text {ST }}$ & $G$ \\
\hline LAP-B & 0.069 & 0.046 & 0.094 & 0.070 & 0.004 & 9.298 \\
GOT-B & 0.032 & 0.012 & 0.020 & 0.021 & 0.000 & 0.407 \\
PGI-B & 0.099 & 0.087 & 0.012 & 0.066 & 0.010 & $7.527^{*}$ \\
$G-6-P D H-A$ & 0.028 & 0.040 & 0.035 & 0.035 & 0.001 & 1.369 \\
6-PGDH-B & 0.107 & 0.160 & 0.064 & 0.110 & 0.017 & $11.342^{* *}$ \\
6-PGDH-C & 0.025 & 0.060 & 0.036 & 0.040 & 0.000 & 1.294 \\
MDH-C & 0.042 & 0.011 & 0.031 & 0.028 & 0.002 & 1.748 \\
Gene pool & 0.057 & 0.059 & 0.042 & 0.053 & 0.006 & \\
\hline
\end{tabular}

$N$, sample size.

Table 3 Allelic differentiation among pooled pollen clouds ('Popocs') of Picea abies

\begin{tabular}{lcccccc}
\hline & \multicolumn{7}{c}{$D_{j}$} \\
\cline { 2 - 5 }$N$ & $\begin{array}{c}\text { Pop. I } \\
700\end{array}$ & $\begin{array}{c}\text { Pop. II } \\
700\end{array}$ & $\begin{array}{c}\text { Pop. III } \\
700\end{array}$ & $\delta$ & $G_{\text {ST }}$ & $G$ \\
\hline LAP-B & 0.011 & 0.029 & 0.037 & 0.026 & 0.001 & 8.047 \\
$G O T-B$ & 0.033 & 0.006 & 0.036 & 0.025 & 0.001 & 2.521 \\
$P G I-B$ & 0.001 & 0.014 & 0.014 & 0.010 & 0.000 & 0.630 \\
$G-6-P D H-A$ & 0.046 & 0.023 & 0.030 & 0.033 & 0.005 & $6.371^{*}$ \\
6-PGDH-B & 0.019 & 0.054 & 0.035 & 0.036 & 0.002 & $6.623^{*}$ \\
6-PGDH-C & 0.031 & 0.014 & 0.038 & 0.028 & 0.001 & 3.061 \\
MDH-C & 0.021 & 0.025 & 0.039 & 0.028 & 0.006 & $10.631^{* *}$ \\
Gene pool & 0.020 & 0.025 & 0.035 & 0.026 & 0.001 & \\
\hline
\end{tabular}

See Table 2 for further explanations.

and 198 alleles, statistically significant heterogeneity among the Pops was observed only at the PGI-B and 6$P G D H-B$ gene loci. Heterogeneity among the Popocs was statistically significant at three loci ( $G-6-P D H-A$, 6-PGDH-B and $M D H-C)$; sample sizes were $7 \times 100=700$ alleles per Popoc.

Ranking of gene loci with regard to heterogeneity among Pops or Popocs depends on the differentiation measure $\delta$ or $G_{\mathrm{ST}}$ used, as the measures are not equivalent (Gregorius \& Roberds, 1986). However, both measures indicate very low levels of allelic differentiation at all loci among the Pops, and differentiation among Popocs is even lower. The 'gene pool' differentiation $D_{j}$ of population $\mathrm{II}$ is highest for the Popocs but lowest if based on the Pops.

\section{Genetic distances between pollen clouds and populations}

Genetic distances $d_{0}$ between Sitpocs and their respective Pops based on allele frequencies are shown in Table 4. The last column shows the genetic distance between the Popoc and the Pop for each population. There are obvious differences between the populations. Significant deviations between Sitpocs and the Pop were observed only four times in population I (counting all gene loci); tree 4 of this population showed significant differences at three of the seven gene loci investigated and had the highest gene pool distance of all Sitpocs. Sitpocs of five trees of population I did not differ significantly from the Pop at any 
Table 4 Allelic distances $d_{0}$ between single tree pollen clouds ('Sitpocs') and the population sample ('Pop'; T 1 to T 7) as well as between the pooled pollen cloud ('Popoc') and the population sample ('Pop'; pooled) for Picea abies

\begin{tabular}{|c|c|c|c|c|c|c|c|c|}
\hline & T 1 & Т 2 & T 3 & T 4 & T 5 & T 6 & T 7 & Pooled \\
\hline \multicolumn{9}{|l|}{ Population 1} \\
\hline$L A P-B$ & 0.044 & 0.104 & 0.047 & 0.048 & 0.103 & 0.053 & 0.082 & 0.018 \\
\hline GOT-B & 0.032 & 0.032 & 0.015 & $0.202^{* * *}$ & 0.068 & 0.008 & 0.088 & 0.011 \\
\hline$P G I-B$ & 0.026 & 0.016 & 0.056 & 0.016 & 0.046 & 0.066 & 0.026 & 0.036 \\
\hline$G-6-P D H-A$ & 0.052 & 0.042 & 0.049 & $0.062^{*}$ & 0.052 & 0.021 & 0.032 & 0.029 \\
\hline $6-P G D H-B$ & 0.051 & 0.136 & 0.061 & 0.086 & 0.031 & 0.041 & 0.031 & 0.046 \\
\hline 6- $P G D H-C$ & $0.135^{*}$ & 0.150 & 0.005 & $0.175^{* *}$ & 0.055 & 0.045 & 0.015 & 0.079 \\
\hline$M D H-C$ & 0.026 & 0.036 & 0.056 & 0.041 & 0.026 & 0.031 & 0.051 & 0.026 \\
\hline Gene pool & 0.052 & 0.074 & 0.041 & 0.090 & 0.054 & 0.038 & 0.046 & 0.035 \\
\hline \multicolumn{9}{|l|}{ Population II } \\
\hline$L A P-B$ & 0.142 & 0.052 & 0.064 & 0.102 & 0.054 & 0.052 & 0.053 & 0.028 \\
\hline$G O T-B$ & 0.046 & 0.076 & 0.084 & 0.017 & 0.077 & 0.117 & 0.096 & 0.044 \\
\hline$P G I-B$ & $0.138^{*}$ & 0.098 & $0.138^{*}$ & 0.058 & $0.188^{* * *}$ & 0.068 & 0.002 & $0.098^{* *}$ \\
\hline$G-6-P D H-A$ & 0.031 & $0.076^{*}$ & 0.051 & 0.056 & $0.076^{*}$ & $0.091^{*}$ & $0.086^{*}$ & $0.062^{* *}$ \\
\hline$G-P G D H-B$ & $0.149^{*}$ & 0.079 & $0.139^{*}$ & $0.174^{* *}$ & 0.099 & $0.139 *$ & 0.056 & $0.108^{*}$ \\
\hline 6-PGDH-C & 0.079 & 0.109 & 0.029 & 0.029 & 0.009 & 0.021 & 0.151 & 0.012 \\
\hline$M D H-C$ & 0.061 & $0.066^{*}$ & $0.071^{* *}$ & 0.051 & 0.010 & 0.046 & 0.051 & $0.048^{*}$ \\
\hline Gene pool & 0.092 & 0.080 & 0.082 & 0.070 & 0.073 & 0.076 & 0.071 & 0.057 \\
\hline \multicolumn{9}{|l|}{ Population III } \\
\hline$L A P-B$ & $0.142^{* *}$ & 0.123 & $0.112^{*}$ & $0.152^{* * *}$ & $0.092^{*}$ & $0.133^{*}$ & $0.112^{*}$ & $0.118^{* * *}$ \\
\hline$G O T-B$ & $0.213^{* * *}$ & 0.098 & 0.072 & 0.008 & 0.052 & 0.102 & $0.162^{*}$ & 0.069 \\
\hline$P G I-B$ & 0.059 & $0.109^{*}$ & 0.089 & 0.011 & 0.079 & $0.141^{*}$ & 0.029 & 0.030 \\
\hline$G-6-P D H-A$ & 0.037 & 0.007 & 0.007 & 0.053 & 0.023 & 0.037 & 0.013 & 0.000 \\
\hline 6-PGDH-B & 0.009 & 0.047 & 0.037 & 0.073 & 0.073 & 0.027 & 0.063 & 0.016 \\
\hline 6-PGDH-C & 0.073 & 0.073 & 0.053 & 0.020 & 0.020 & 0.020 & $0.143^{*}$ & 0.046 \\
\hline$M D H-C$ & 0.041 & 0.011 & 0.011 & 0.016 & $0.091^{* * *}$ & 0.011 & 0.006 & 0.022 \\
\hline Gene pool & 0.082 & 0.067 & 0.054 & 0.047 & 0.061 & 0.067 & 0.075 & 0.043 \\
\hline
\end{tabular}

Asterisks indicate statistically significant differences between frequency distributions (log likelihood ratio test) at the $5 \%$ level $\left({ }^{*}\right)$, $1 \%$ level $\left.{ }^{(* *}\right)$ and $0.1 \%$ level $(* * *)$.

locus, and there was no significant deviation between the Popoc and the Pop at any of the examined gene loci.

Significant deviations between Sitpocs and the Pop were observed 13 times in population II and 12 times in population III (counting all gene loci). All Sitpocs of populations II and III showed significant deviations between their respective frequency distributions and the Pop for at least one gene locus. The Popoc differed significantly from the Pop in population II at four of the seven gene loci examined; the highest single locus distance between the Popoc and the Pop was observed for $L A P-B$ in population III.

In spite of considerable distances between Sitpocs and Pops at single loci, gene pool distances are only moderate, as there are (with the exception of T 4 of population I) no Sitpocs that show high differences at most investigated gene loci. The gene pool genetic distance between the Popoc and the Pop is lower than the respective distances between any Sitpoc and the Pop for each population. Hence, the Popoc represents the population better than any Sitpoc. However, allelic distances at single loci indicate that the Popoc of population II is not representative for the population.

\section{Differentiation among single tree pollen clouds}

Allelic differentiation among Sitpocs was calculated for each population separately (Table 5). Significant differentiation among Sitpocs was observed for two loci (populations I and II) and three loci (population III); the set of loci showing statistically significant heterogeneity ( $\log$ likelihood test) differed between populations.

Differentiation among Sitpocs within populations is low; $\delta$ is of the same order of magnitude as differentiation between the Pops, $G_{\mathrm{ST}}$ values are slightly higher (compare Tables 2 and 5). $D_{j}$-values are comparatively high for several Sitpocs at single loci (e.g. for T 4 of population I at $G O T-B$ ), but the values are not consistent over all loci, as Sitpocs that show marked differen- 
Table 5 Differentiation among single tree pollen clouds ('Sitpocs') of Picea abies

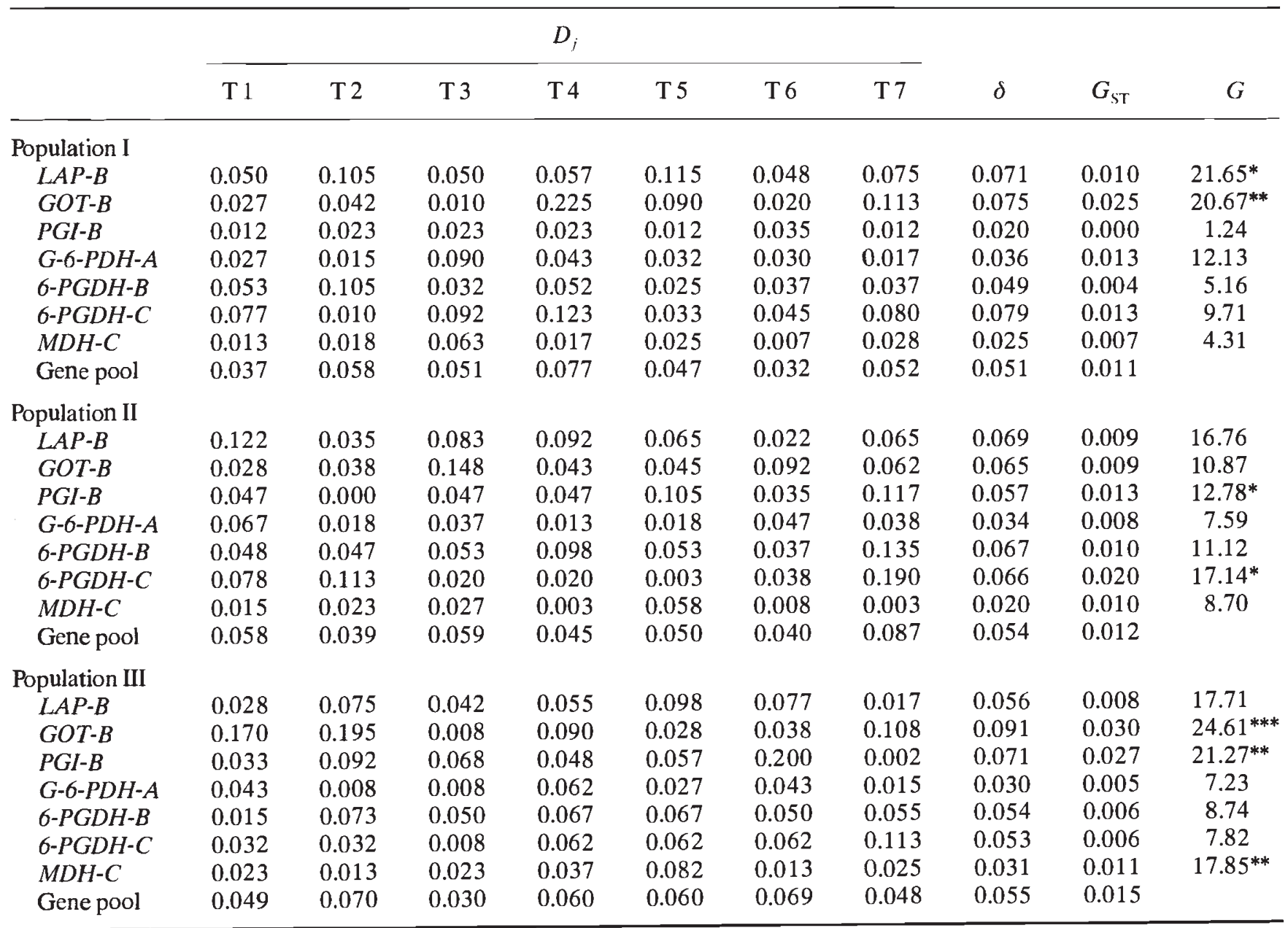

See Table 2 for further explanations ( $G$-test: 4 d.f. for $L A P-B$ and 2 d.f. for all other loci).

tiation from the remainder at some loci are representative of all pollen clouds at others. Accordingly, gene pool $D_{i}$-values are homogeneous and low.

Average allelic distances between Sitpocs of the same and of two different populations are compared in Table 6. Arithmetic means of gene pool allelic distances $d_{0}$ were computed over all pairwise combinations of Sitpocs both within the same population and between two different populations. The average gene pool genetic distance between two Sitpocs of population I is (slightly) higher than the average gene pool genetic distance between one Sitpoc from population I and the other from population II. This tendency is even more pronounced for population III in place of population I.

The impression of the absence of genetic differentiation at the population level is corroborated by the results of the hierarchical analysis of differentiation among all Sitpocs (Table 7). The proportion of the total differentiation $H_{\mathrm{T}}$ due to variation within populations $\left(G_{\mathrm{SP}}\right)$ is low, but positive for all gene loci. Variation
Table 6 Average gene pool genetic distances $d_{0}$ (Gregorius, 1974) between single tree pollen clouds ('Sitpocs') of the same population (diagonal line) and of two different populations of Picea abies

\begin{tabular}{lccc}
\hline & \multicolumn{3}{c}{ Population } \\
\cline { 2 - 4 } Population & I & II & III \\
\hline I & \multirow{2}{*}{0.072} & 0.071 & 0.076 \\
II & & 0.064 & 0.066 \\
III & & & 0.072
\end{tabular}

among populations is almost absent, as $G_{\mathrm{PT}}$ is very close to 0 for all loci, and for four of the seven loci even slightly negative. Wright (1969, p. 295) mentions the possibility of negative values of differentiation parameters arising from a prevailing avoidance of consanguineous matings. However, the marginally negative 
values reported here may simply be an effect of the limited sample size.

\section{Differentiation of rare alleles}

The quantitative measures of genetic diversity and differentiation reported so far are insensitive for the detection of patterns of differentiation of alleles that are rare in all demes. Hence, qualitative differentiation of rare alleles among Sitpocs may go unnoticed if the interpretation solely rests on measures of quantitative differentiation.

'Private' alleles, i.e. alleles which are unique to single populations, are important indicators of gene flow among populations (Slatkin, 1985). Four 'private' alleles that are unique to only one Sitpoc of the respective population, i.e. which were not observed in the pollen cloud of any other tree of the same population,

Table 7 Hierarchical analysis of gene diversity (Nei, 1973) for all single tree pollen clouds ('Sitpocs') of Picea abies

\begin{tabular}{lcrc}
\hline & $H_{\mathrm{T}}$ & \multicolumn{1}{c}{$G_{\mathrm{PT}}$} & $G_{\mathrm{SP}}$ \\
\hline LAP-B & 0.326 & -0.001 & 0.012 \\
$G O T-B$ & 0.498 & -0.003 & 0.025 \\
$P G I-B$ & 0.384 & -0.003 & 0.015 \\
$G-6-P D H-A$ & 0.142 & 0.003 & 0.011 \\
6-PGDH-B & 0.412 & 0.001 & 0.009 \\
6-PGDH-C & 0.499 & -0.002 & 0.016 \\
MDH-C & 0.094 & 0.004 & 0.012 \\
Gene pool & 0.325 & -0.001 & 0.015 \\
\hline
\end{tabular}

$H_{\mathrm{T}}$, total gene diversity; $G_{\mathrm{PT}}$, proportion of $H_{\mathrm{T}}$ resulting from differentiation among populations; $G_{\mathrm{SP}}$, proportion of $H_{\mathrm{T}}$ resulting from differentiation among 'Sitpocs' within populations. were identified. The allele $L A P-B_{5}$ was identified twice in the Sitpoc of T 5 of population I. As this tree is heterozygous $B_{I} B_{5}$ at the $L A P-B$ locus and no other tree of the population sample shows the $B_{5}$ allele, the occurrence of the $B_{5}$ allele in this tree's Sitpoc strongly suggests selfing. The allele $G-6-P D H-A_{3}$ was identified once in the pollen cloud of T 7 and the allele 6-PGDH$B_{4}$ once in the pollen cloud of T 4 of population II. The allele $M D H-C_{I}$ is unique to the pollen cloud of T 3 of population III; it was also observed only once. As the sample sizes of all Sitpocs were 100 , the relative frequencies of private alleles are 2 per cent for $L A P-B_{5}$ in population $I$ and 1 per cent for three other unique alleles. In summary, the frequency of private alleles is very low.

Two other rare alleles were observed in all Pops and most Sitpocs. Their relative frequencies are shown in Table 8. A coefficient of dispersion (CD; last column of Table 8) $\gg 1$ indicates strong deviation from a Poisson distribution because of clumped samples (Sokal \& Rohlf, 1981, p. 87). Hence, there is evidence for a clumping of rare alleles in particular Sitpocs for $L A P$ $B_{3}$ in population I and for $G O T-B_{1}$ in population II. However, the general impression is a remarkably homogeneous distribution of these rare alleles among the Sitpocs. The nonappearance of the alleles in two Sitpocs may be caused by the limited sample size, as the probability of the absence of an allele with an actual relative frequency of 2 per cent in a Sitpoc (which is a good approximation of the observed frequencies in all Popocs) in a random sample of 100 alleles is $(1-0.02)^{100}=0.133$.

\section{Estimation of outcrossing rates}

Single tree multilocus outcrossing rates based on the estimation procedure of Ritland \& Jain (1981) are

Table 8 Relative frequencies (in \%) of two rare alleles in single tree pollen clouds of Picea abies ('Sitpocs'; T 1 to T 7), the pooled pollen cloud ('Popocs'; pooled), and the population sample ('Pop'; Population)

\begin{tabular}{lcccccccccc}
\hline Allele & T 1 & T 2 & T 3 & T 4 & T 5 & T 6 & T 7 & Pooled & Population & CD \\
\hline LAP-B 3 & & & & & & & & & & \\
$\quad$ Population I & 8 & 0 & 2 & 1 & 1 & 1 & 1 & 2.00 & 1.02 & 3.67 \\
$\quad$ Population II & 1 & 4 & 1 & 1 & 2 & 1 & 2 & 1.71 & 1.52 & 0.72 \\
$\quad$ Population III & 1 & 1 & 5 & 0 & 2 & 4 & 2 & 2.14 & 4.54 & 1.47 \\
GOT-B, & & & & & & & & & & \\
$\quad$ Population I & 4 & 3 & 3 & 3 & 0 & 1 & 1 & 2.14 & 2.04 & 1.00 \\
$\quad$ Population II & 5 & 4 & 1 & 1 & 0 & 1 & 6 & 2.57 & 2.02 & 2.19 \\
$\quad$ Population III & 3 & 3 & 1 & 2 & 1 & 1 & 1 & 1.71 & 1.95 & 0.53 \\
\hline
\end{tabular}

CD, coefficient of dispersion (Sokal \& Rohlf, 1981, p. 87) indicating deviation from a Poisson distribution. 
Table 9 Multilocus estimates $\left(t_{\text {in }}\right)$ of single tree outcrossing rates for Picea abies. multi- $\left(t_{\mathrm{m}}\right)$ and average single locus $\left(t_{\mathrm{s}}\right)$ estimates of population outcrossing rates and standard deviations of all estimates (Ritland \& Jain, 1981)

\begin{tabular}{|c|c|c|c|c|c|c|c|c|c|}
\hline & \multicolumn{7}{|c|}{ Single tree $t_{\mathrm{m}}$} & \multicolumn{2}{|c|}{ Population } \\
\hline & $\mathrm{T} 1$ & T 2 & T 3 & T 4 & T 5 & T 6 & T 7 & $t_{\mathrm{m}}$ & $t_{\mathrm{s}}$ \\
\hline \multicolumn{10}{|l|}{ Population I } \\
\hline Outcrossing rate & 1.05 & 1.03 & 1.00 & 0.84 & 0.98 & 0.95 & 0.94 & 0.96 & 0.99 \\
\hline Standard deviation & 0.09 & 0.10 & 0.14 & 0.10 & 0.11 & 0.05 & 0.05 & 0.02 & 0.02 \\
\hline \multicolumn{10}{|l|}{ Population II } \\
\hline Outcrossing ra & 1.25 & 0.96 & 0.96 & 1.09 & 1.01 & 1.00 & 1.00 & 1.01 & 1.01 \\
\hline Standard deviation & 0.03 & 0.04 & 0.05 & 0.03 & 0.17 & 0.05 & 0.22 & 0.01 & 0.02 \\
\hline \multicolumn{10}{|l|}{ Population III } \\
\hline Outcrossing rate & 0.97 & 0.91 & 0.96 & 0.99 & 1.02 & 0.98 & 1.02 & 0.95 & 0.90 \\
\hline Standard deviation & 0.05 & 0.06 & 0.04 & 0.06 & 0.16 & 0.06 & 0.11 & 0.02 & 0.02 \\
\hline
\end{tabular}

presented in Table 9. Average single locus $\left(t_{\mathrm{s}}\right)$ and multilocus $\left(t_{\mathrm{m}}\right)$ estimates of population outcrossing rates and standard deviations of all values are listed as well. Population estimates differ only slightly from 1 , i.e. complete outcrossing. The same holds true for single tree estimates with the exception of $\mathrm{T} 4$ of population I, which shows an appreciable level of selfing $\left(t_{\mathrm{m}}=0.84\right.$, i.e. $\left.s=0.16\right)$. T 1 and $\mathrm{T} 4$ of population II show an outcrossing rate significantly above 1 , indicating violation of the assumptions of the mixed-mating model.

\section{Discussion}

\section{Differentiation among populations}

Genetic differentiation among the Pops is very low (Table 2). Interestingly, a more comprehensive genetic inventory in Picea abies populations of the Sauerland gave similar results. The same set of seven polymorphic gene loci was used to observe patterns of genetic variation and differentiation among 16 plantations. Gene pool differentiation was $\delta=0.053$ and $G_{\mathrm{ST}}=0.009$ (Finkeldey, 1993, p. 75). Poor differentiation at isozyme gene loci in spite of considerable allelic diversity is a commonly observed phenomenon; both extensive gene flow between populations and a uniform selective regime favouring the same genotype in different environments can account for low differentiation among populations. The significance of the latter explanation for spatial patterns of genetic variation at isozyme gene loci is proposed elsewhere (Finkeldey, 1993). Hence, the low observed differentiation at isozyme marker loci may not be representative of the genome as a whole.
Notwithstanding these peculiarities of isozyme marker loci, the observed differentiation is extraordinarily low if compared with other genetic inventories in Picea abies populations. As expected, higher differentiation both at the gene pool level and at all five corresponding single gene loci was observed in a rangewide survey of Norway spruce (Lagercrantz \& Ryman, 1990). Analogous results were obtained in three investigations covering a smaller geographical range comparable to the size of the Sauerland as well. Although differentiation is only moderate among Picea abies populations of South Germany's Black Forest (Konnert \& Franke, 1991), of the Wallis (Switzerland; Stutz, 1990), and of Northern Italy (Giannini et al., 1991), it is still markedly higher than differentiation among populations of the Sauerland.

By far the most probable explanation for the extraordinarily low differentiation is the supposed joint origin of all (investigated) populations of the Sauerland from a very small central European part of the natural distribution range of the species. According to the results of Lagercrantz \& Ryman (1990), central European populations of Picea abies are depauperate of genetic variation and form a poorly differentiated complex. Most (if not all) Norway spruce plantations of the Sauerland originate from a small fraction of the central European distribution range of the species.

\section{Differentiation among pooled pollen clouds}

Differentiation among Popocs of the three populations (Table 3) was even lower than differentiation among the Pops. While this might partially reflect the larger sample size and hence smaller sampling error, the effect may also be interpreted as a hint of extensive gene flow via pollen among populations. Because of the 
supposed same origin of (nearly) all plantations of the Sauerland, the genetic structure of the background pollen pool, i.e. fertilizing pollen not produced by the plantations themselves, might be virtually identical for the three populations. Obviously, in that instance high frequencies of fertilization by background pollen in all populations will decrease genetic differentiation among Popocs. This hypothesis is reinforced by the comparisons of average genetic distances between Sitpocs both of the same and of two different populations (Table 6). Results indicated that there is no substructure differentiating Sitpocs at the population level (Table 7).

\section{Representativeness and differentiation of pollen allele frequencies}

While, with the exception of T 4, Sitpocs of population I represented the population fairly well, and there was a very good correspondence between the Popoc and the Pop, this does not hold true for populations II and III (Table 4). The reasons for the different results depending on the investigated population are obscure. All populations are pure spruce plantations growing under similar environmental conditions; population size is the only obvious differentiating criterion. It may be speculated that the smaller size of population I (plantation area is 2.8 ha compared with 14.3 ha of population II and 6.8 ha of population III) promotes representativeness of Sitpocs, but this conclusion is contradicted by the apparently large gene flow within all populations and the probable absence of a family structure (see below).

No clear differences between the populations were observed with regard to differentiation among Sitpocs (Table 5). Gene pool estimates of $\delta$ vary between 0.051 and 0.055 ; gene pool $G_{\mathrm{ST}}$ is between 0.011 and 0.015 . The highest single locus differentiation among Sitpocs was observed at the $G O T-B$ locus in population III, but even at that locus both $\delta=0.091$ and $G_{\mathrm{ST}}=0.030$ indicate only small levels of genetic differentiation.

Murawski \& Hamrick (1991) measured heterogeneity among pollen allele frequencies for nine tropical tree species that occur on Barro Colorado Island. They found gene pool $G_{\mathrm{ST}}$-values (mean $F_{\mathrm{SF}}$ according to their notation) between 0.064 and 0.259 . Comparatively low population densities of tropical tree species probably lead to small genetic neighbourhoods and hence heterogeneous pollen pools. Gibson \& Hamrick (1991) investigated the heterogeneity in pollen allele frequencies among seed trees of a Pinus pungens population. The gene pool differentiation $G_{\mathrm{ST}}$ among the 'Sitpocs' of nine trees was 0.123 , which means that the heterogeneity among Sitpocs of this pine is much higher than the heterogeneity among spruce Sitpocs. There are no obvious explanations for the striking differences between these conifer species, as a high proportion of selfings in Pinus pungens is unlikely (see below). Significant heterogeneity among the pollen pool of 47 seed trees of a Picea glauca population was observed by Cheliak et al. (1985).

\section{Estimation of outcrossing rates}

Both single tree and population estimates indicate high levels of outcrossing rates in all populations. While the average single locus outcrossing rate $t_{\mathrm{s}}$ is slightly higher than the multilocus population estimate $t_{\mathrm{m}}$ for population I, the reverse is true for population III; no difference is observed between both estimates in population II (Table 9). The outcome of population III $\left(t_{\mathrm{m}}>t_{\mathrm{s}}\right)$ is usually interpreted as an indication of a family structure resulting in a certain amount of inbreeding other than selfing (Shaw \& Allard, 1982). However, all investigated populations are plantations; hence, the existence of a family structure in any population is very improbable.

For most seed trees, multilocus estimates of outcrossing rates are not significantly different from one, i.e. complete outcrossing. Exeptions are T 1 and T 4 of population II with estimates of outcrossing rates significantly above one, indicating violations of model assumptions and hence requiring caution in the interpretation of results based on a mixed-mating model. A strong indication of selfing occurring in low frequencies was inferred for $\mathrm{T} 5$ of population I from the investigation of the rare allele $L A P-B_{5}$. However, the estimate of the outcrossing rate $\left(t_{\mathrm{m}}\right)$ of this tree is not significantly different from one. $\mathrm{T} 4$ of population $\mathrm{I}$ is the only tree with an estimated outcrossing rate clearly below one $\left(t_{\mathrm{m}}=0.84\right)$. The Sitpoc of this tree has the lowest pollen gene pool diversity of all seed trees (Table 1), the highest genetic distance of the Sitpocs of population I from the Pop (Table 4), and the highest differentiation $D_{j}$ of all Sitpocs of population I (Table 5). It seems reasonable to explain these peculiarities by an extraordinarily high proportion of selfs in its offspring $(s=0.16)$.

Assuming regular segregation, the genetic distance $d_{0}$ between allele frequencies of pollen produced by two plants equals the allelic distance between these plants (each plant is regarded as a 'population'). For diploids $d_{0}=0$, if the plants share both alleles, $d_{0}=0.5$ if the plants share one allele, and $d_{0}=1$ if the plants do not share an allele. Hence, high differentiation among pollen allele frequencies of selfed progenies of different seed plants is expected if the plants differ in their genotypes. It is difficult to imagine mechanisms leading to a structure of the outcrossed pollen pools that could counteract differentiation among Sitpocs caused by a high proportion of selfs. Hence, a low selfing rate is a 
necessary precondition for the homogeneity of Sitpocs if plants differ in their genotypes at a specific gene locus. As the investigated seed trees differ in their genotypes for most gene loci in all populations, the observed low differentiation among their Sitpocs is another clear indication of low selfing rates.

The observation of high population outcrossing rates in Picea abies populations is in good agreement with the results of Morgante et al. (1991), whose estimates of multilocus population outcrossing rates $t_{\mathrm{m}}$ in two Italian populations were 0.955 and 0.956 . The estimates of Muona et al. (1991) were $t_{\mathrm{m}}=0.83$ for a Slovakian and $t_{\mathrm{m}}=0.74$ for a Finnish population. Cheliak et al. (1985) did not find significant deviations from complete outcrossing in a Picea glauca population, Boyle \& Morgenstern (1986) observed population outcrossing rates $t_{\mathrm{m}}$ ranging from 0.891 to 0.976 in six populations of Picea mariana, and Shea (1987) reported population outcrossing rates of Picea engelmannii in the range of 0.80 to 0.93 . Hence, there is little doubt that spruce populations are predominantly outbreeding.

Müller (1977) estimated selfing proportions of single Picea abies trees based on the observation of rare alleles. His estimates of maximum selfing rates of eight spruces range from 0.073 to 0.177 . Results of Lundkvist (1979), who investigated five Norway spruce trees with rare alleles at a gene locus, are more heterogeneous; selfing rates varied between 0 and 0.257 .

Similar results, i.e. high and comparatively uniform outcrossing rates, were reported from several other conifers. The multilocus outcrossing rate of all of the Pinus pungens trees investigated by Gibson \& Hamrick (1991; see above) were not significantly different from one. High and homogeneous outcrossing rates of single trees were observed in populations of Pinus banksiana as well (Fu et al., 1992). Differences between estimates of single tree outcrossing rates, some trees being predominantly or completely outbreeders and others showing high proportions of selfings, were reported from Pinus monticola (El-Kassaby et al., 1993) and Thuja occidentalis (Perry \& Knowles, 1990).

\section{The mating system}

Sitpocs within a random mating population are expected to be homogeneous, each pollen cloud reflecting the allelic structure of the parent population. However, mere homogeneity among Sitpocs does not prove random mating, as a possible allelic differentiation between the parent population and pollen clouds is disregarded. Hence, it seems more appropriate to measure the degree of deviations from random mating by allelic distances between Pops and Sitpocs than by the differentiation among Sitpocs.

Statistically significant differences between Sitpocs and Pops were observed for at least one gene locus for all seed trees of population II and for two trees of population I (Table 4). Accordingly, the populations do not mate at random, but deviations from random mating are rather small. This holds true particularly for population $\mathrm{I}$, as on average $d_{0}$ distances are smallest in this population and no statistically significant differences were detected for five of the seven trees investigated. Deviations from random mating are most distinct in population II, as genetic distances between Sitpocs and Pops are highest in this population.

\section{Gene flow}

Neither genetic distances between Pops and Sitpocs nor differentiation among Sitpocs are direct measures of the amount of gene flow within populations. However, the observed low differentiation and small genetic distances clearly point to extensive gene flow and large genetic effective population sizes.

This inference is corroborated by the low frequencies of private alleles in all Sitpocs. Following the argument of Slatkin (1985), low frequencies of private alleles are reliable indicators of high rates of gene flow among populations. His line of reasoning may be extended to gene flow within populations as well; hence, the observed low frequencies of private alleles within Sitpocs (see 'differentiation of rare alleles' in Results) point towards large gene flow among the trees. Another hint at effective gene flow is given by the uniform distribution of the rare alleles $L A P-B_{3}$ and $G O T-B_{l}$ (Table 8). Obviously, the few trees spreading these alleles by their pollen were represented in the Sitpocs of most trees in good agreement with the frequency of the alleles in the populations.

In conclusion, it appears that pollination by wind is a very effective means of gene flow by pollen in pure plantations of Picea abies. High population density, large production of pollen by the majority of trees of plantations, and synchronization of flowering periods promote pollen flow. Possible variation of male fertilities of individual pollen donors affect pollen allele frequencies only moderately, as the effective number of pollen donors is large for all seed trees. This conclusion contrasts with the results of Xie \& Knowles (1992), who found considerable variation in the fertilities of individual pollen donors among seed trees in a small plantation of Norway spruce. A few pollen donors fertilized most seeds of single mother trees, and the set of successful pollen donors differed among seed trees. Obviously, this pattern results in strong differentiation among Sitpocs. The contrasting results are 
easily explained by the widely differing population sizes; the isolated population investigated by Xie \& Knowles (1992) comprised only 27 trees whereas the number of potential pollen donors within the plantations of the Sauerland amounts to hundreds, if not thousands.

The size of the investigated plantations was determined in accordance with administrative subdivisions of large tracts of forest mostly dominated by Norway spruce. Hence, population sizes may be much larger than the sizes of plantations if a population is defined as a genetic unit of interbreeding individuals. The low differentiation among the Popocs (Table 3) and the absence of differentiation between Sitpocs at the population level (Tables 6 and 7) both indicate that population sizes considerably exceed administrative divisions. In fact, the results do not rule out the conception of a principally homogeneous dissemination of genetic information via pollen throughout regions as large as the Sauerland.

Gene flow as an evolutionary force counteracts processes of adaptive and nonadaptive genetic differentiation. The evidence for the effectiveness of gene flow by pollen within and among Picea abies populations presented here strongly suggests that the formation of genetically differentiated subpopulations within large tracts of Norway spruce forests is unlikely on a small geographical scale. Adaptive changes of genetic structures in response to patchiness of the environment will to a great extent be revoked by pollen flow during reproduction. This strategy offers clear advantages if temporal changes of the environment dominate. However, it is accompanied by a permanently large genetic load, which may be tolerated because of the abundant seed production of Norway spruce.

\section{Acknowledgements}

The author is grateful to E. Gillet, H.-R. Gregorius, H. H. Hattemer and K. Krutovskii for helpful comments on the manuscript. Experimental investigations were supported by the Forstgenbank Obereimer of the Forstverwaltung Nordrhein-Westfalen.

\section{References}

Bergmann, F. 1973. Genetische Untersuchungen bei Picea abies mit Hilfe der Isoenzym-Identifizierung. II. Genetische Kontrolle von Esterase- und Leucinaminopeptidase-Isoenzymen im haploiden Endosperm ruhender Samen. Theor. Appl. Genet., 43, 222-225.

BOYLE, T. J. B. AND MORGENSTERN, E. K. 1986. Estimates of outcrossing rates in six populations of black spruce in central New Brunswick. Silvae Genet., 35, 102-106.
BROWN, A. H. D. AND ALLARD, R. W. 1970. Estimation of the mating system in open-pollinated maize populations using isozyme polymorphisms. Genetics, 66, 133-145.

BROWN, A. H. D., BARRETT, S. C. H. AND MORAN, G. F. 1985. Mating system estimation in forest trees: models, methods and meanings. In: Gregorius, H. R. (ed.) Population Genetics in Forestry, Lecture Notes in Biomathematics, vol. 60, pp. 32-49. Springer-Verlag, Berlin.

CHEliak, W. M., PITEL, J. A. AND MURRAy, G. 1985. Population structure and the mating system of white spruce. Can.J. Forest Res., 15, 301-308.

CROW, J. F. AND KIMURA, M. 1970. An Introduction to Population Genetics Theory. Harper and Row, New York.

EL-KASSABY, Y. A., MEAGHER, M. D. AND DAVIDSON, R. 1993. Temporal variation in the outcrossing rate in a natural stand of western white pine. Silvae Genet., 42, 131-135.

FINKELDEY, R. 1993. Die Bedeutung allelischer Profile für die Konservierung genetischer Ressourcen bei Waldbäumen, Göttingen Research Notes in Forest Genetics, vol. 14. Abteilung für Forstgenetik, Göttingen.

FU. Y. B., KNOWLES, P. AND PERRY, D. J. 1992. Pollen pool heterogeneity in jack pine (Pinus banksiana Lamb.): a problem for estimating outcrossing rates? Theor. Appl. Genet., 83, 500-508.

GEBUREK, Th. AND VON WUEHLISCH, G. 1989. Linkage analysis of isozyme gene loci in Picea abies (L.) Karst. Heredity, 62, 185-191.

GIANNINI, R., MORGANTE, M. AND VENDRAMIN, G. G. 1991. Allozyme variation in Italian populations of Picea abies (L.) Karst. Silvae Genet., 40, 160-166.

GIBSON, J. P. AND HAMRICK, J. L. 1991. Heterogeneity in pollen allele frequencies among cones, whorls, and trees of Table Mountain pine (Pinus pungens). Am. J. Bot,, 78, 1244-1251.

GOVINDARAJU, D. R. 1988. A note on the relationship between outcrossing rate and gene flow in plants. Heredity, 61, 401-404.

GREGORIUS, H.-R. 1974. Genetischer Abstand zwischen Populationen. I. Zur Konzeption der genetischen Abstandsmessung. Silvae Genet., 23, 22-27.

GREGORIUS, H.-R. 1985. Measurement of genetic differentiation in plant populations. In: Gregorius, H. R. (ed.) Population Genetics in Forestry, Lecture Notes in Biomathematics, vol. 60, pp. 276-285. Springer-Verlag, Berlin.

GREGORIUS, H.-R. 1987. The relationship between the concepts of genetic diversity and differentiation. Theor. Appl. Genet., 74, 397-401.

GREGORIUS, H.-R. AND ROBERDS, J. H. 1986. Measurement of genetical differentiation among subpopulations. Theor. Appl. Genet., 71, 826-834.

KONNERT, M. AND FRAnke, A. 1991. Die Fichte (Picea abies (L.) Karst.) im Schwarzwald: Genetische Differenzierung von Beständen. Allg. Forst- u. J.-Ztg., 162, 100-106.

LAGERCRANTZ, U. AND RYMAN, N. 1990. Genetic structure of Norway spruce (Picea abies): concordance of morphological and allozymic variation. Evolution, 44, 38-53.

LUNDKVIST, K. 1979. Allozyme frequency distributions in four Swedish populations of Norway spruce (Picea abies K.). I. 
Estimations of genetic variation within and among populations and a mating system parameter. Hereditas, 90, 127-143.

MORGANTE, M., VENDRAMIN, G. G. AND ROSSI, P. 1991. Effects of stand density on outcrossing rate in two Norway spruce (Picea abies) populations. Can. J. Bot., 69, 2704-2708.

MULLER, G. 1977. Untersuchungen über die natürliche Selbstbefruchtung in Beständen der Fichte (Picea abies (L.) Karst.) und Kiefer (Pinus sylvestris L.). Silvae Genet., 26, 207-217.

MUONA, O., YAZDANI, R. AND LINDQvisT, G. 1987. Analysis of linkage in Picea abies. Hereditas, 106, 31-36.

MUONA, O., PAULE, L., SZMIDT, A. E. AND KÄRKKAINEN. K. 1990. Mating system analysis in a Central and Northern European population of Picea abies. Scand. J. Forest Res., 5, 97-102.

MURAWSKI, D. A. AND HAMRICK, J. L. 1991. The effect of the density of flowering individuals on the mating systems of nine tropical tree species. Heredity, 67, 167-174.

NEI, M. 1973. Analysis of gene diversity in subdivided populations. Proc. Natl. Acad. Sci. U.S.A., 70, 3321-3323.

PERRY, D. J. AND KNOWLES, P. 1990. Evidence of high self-fertilization in natural populations of eastern white cedar (Thuja occidentalis). Can. J. Bot., 68, 663-668.

RITLAND, K. 1990. A series of FORTRAN computer programs for estimating plant mating systems. J. Hered., 81, 235-237.

RITLAND, K. AND EL-KASSABY, Y. A. 1985. The nature of inbreeding in a seed orchard of Douglas fir as shown by an efficient multilocus model. Theor. Appl. Genet., 71, 375-384.

RITLAND, K. AND JAIN, S. 1981. A model for the estimation of outcrossing rate and gene frequencies using $n$ independent loci. Heredity, 47, 35-52.
SCHOEN, D. J. AND CLEGG, M. T. 1984. Estimation of mating system parameters when outcrossing events are correlated. Proc. Natl. Acad. Sci. U.S.A., 81, 5258-5262.

SHAW, D. V. AND ALLARD, R. W. 1982. Estimation of outcrossing rates in Douglas-fir using isozyme markers. Theor. Appl. Genet., 62, 113-120.

SHAW, D. V., KAHLER, A. L. AND ALLARD, R. W. 1981. A multilocus estimator of mating system parameters in plant popula tions. Proc. Natl. Acad. Sci. U.S.A., 78, 1298-1302.

SHEA, K. L. 1987. Effects of population structure and cone production on outcrossing rates in Engelmann spruce and subalpine fir. Evolution, 41, 124-136.

SLATKIN, M. 1985. Rare alleles as indicators of gene flow. Evolution, 39, 53-65.

SOKAL, R. R. AND ROHLF, F. J, 1981. Biometry, 2nd edn. W. H. Freeman, San Francisco.

STuTZ, H. P. 1990. Eigenschaften und Ursachen der genetischen Differenzierung der Fichte im Wallis (Schweiz). In: Hattemer, H. H. (ed.) Erhaltung forstlicher Genressourcen, Schriften a. d. forstl. Fak. d. Univ. Göttingen u. d. Nieders. forstl. Versuchsanst., vol. 98, pp. 99-114. J. D. Sauerländer's Verlag, Frankfurt am Main.

SWOFFORD, D. L. AND SELANDER, R. B. 1981. BIOSYS-1: a FORTRAN program for the comprehensive analysis of electrophoretic data in population genetics and systematics. J. Hered., 72, 281-283.

WRIGHT, s. 1969. Evolution and the Genetics of Populations, vol. 2, The Theory of Gene Frequencies. University of Chicago Press, Chicago.

XIE, C. Y. AND KNOWLES, P. 1992. Male fertility variation in an open-pollinated plantation of Norway spruce (Picea abies). Can. J. Forest Res., 22, 1463-1468. 